\title{
3- Comparative studies on the effect of aspartame (artificial sweetener) and stevia (natural sweetener) on liver of male albino rat
}

\author{
N. A. El-Shinnawy, S. A. Abd Elmageid, H. M. Abd Elhamied \\ Department of Zoology, Women College for Arts, Science and Education, Ain shams \\ university, Egypt.
}

\begin{abstract}
Caloric sweetener sucrose is an essential component of modern diet. However sucrose diet has an adverse effect on body weight and is associated with medical complications. So, substituting sucrose with low calorie sweeteners either synthetic as aspartame or natural as stevia is an efficacious weight management strategy. In the present investigation, total numbers of 64 albino rats were divided into four groups: the first group served as control receiving distilled water. The second group represented the sucrose group receiving $10 \%$ sucrose solution (weight by volume). The third group served as aspartame group receiving aspartame $(75 \mathrm{mg} / \mathrm{kg}$ body weight). The fourth group represented stevia group and received stevia ( $40 \mathrm{mg} / \mathrm{kg}$ body weight). Rats were subjected to different experimental regimens for two durations, short duration (30 days) and long duration (90 days). Histological investigation of liver sections from aspartame treated rats revealed fatty degeneration, necrosis of hepatic cells, dilatation and congestion of the central blood vessels with distortion of normal lobular architecture with increase in collagenous fibers while stevia treatment illustrated preserved normal hepatic pattern. Histochemical staining of Best Carmine stain and bromophenol blue in liver tissue revealed significant decrease in glycogen content and protein content respectively in liver aspartame group followed by sucrose group. On the other hand, image analysis of liver sections stained with Sudan III demonstrated significant elevation in fat content in sections from aspartame treated group followed by sucrose group when compared to control group. Stevia administration revealed no histological or histochemical changes in the liver tissue sections compared to control group.
\end{abstract}

Key words: Sucrose; Aspartame; Stevia; Histopathology.

\section{Introduction}

Sugars are essential component of the modern diet, contributing not only by amounts naturally occurring in many fruits, vegetables, and nuts but also by sweeteners added to processed foods and beverages. Because these sweeteners give metabolized energy to the diet, they are called caloric sweeteners (White, 2014).

Sucrose is one of the caloric sweeteners extracted from sugar cane. It is traditionally used in human nourishment due to its pleasant taste, nutritious value and low cost production (Adegoke et al., 2012). Nevertheless, sucrose sweetened beverages and high sucrose diets have adverse effects on body weight (Johnson et al., 2007) and are associated with medical complications, such as increasing risk for type II diabetes, obesity, cardiovascular diseases (Anton et al., 2010) and fatty liver in rodents (Bizeau and Pagliassotti, 2005).

Corresponding author: Hadeer.mohsen1@hotmail.com 
Therefore, substituting sucrose with low calorie sweeteners may be an efficacious weight management strategy (Anton et al., 2010). So, individuals consuming artificially sweetened beverages may have switched to artificial sweeteners after gaining weight as an attempt to lose weight (Elfhag et al., 2007).

Aspartame (L- aspartyl- L-phenylalanine methyl ester) is one of the most widely used artificial, low calorie sweeteners (Mourad, 2011). It is 200 times sweeter than sucrose. It has been used in many different types of products including soft drinks, desserts, yogurt, chewable multi-vitamins, breakfast cereals, tabletop sweeteners and pharmaceuticals (Marinovich et al., 2013).

Yet, aspartame is metabolized in the gastrointestinal tract to aspartic acid, methanol and phenylalanine. Methanol is then oxidized to formaldehyde and latter to formic acid. Formic acid is considered the principal metabolite responsible for deleterious effects of acute intoxication by methanol in humans and animals (Portela et al., 2007). Moreover, chronic exposure to aspartame was reported to cause headache, dizziness, anxiety, depression, and behavioral disturbances in experimental animals (Ashok et al., 2013).

Furthermore, long-term consumption of aspartame leads to hepatocellular injury. Many histological and histopathological alterations have also been reported in liver sections from aspartame-treated rats (Alkafafy et al., 2015) and alters the redox status of the liver with deleterious effects on liver antioxidant status (Ashok and Sheeladevi, 2015).

Stevia rebaudiana Bertoni is a natural, sweet-tasting calorie free botanical herb that has received increasing industrial and scientific attention in recent years (Abd Elwahab et al., 2017). Stevia is the common name for the extract stevioside (Lemus-Mondaca et al., 2012).

These steviosides are diterpene glycosides obtained from the leaves of stevia plant. Stevia leaves are used as a sugar substitute or as an alternative to artificial sweeteners that is why it is called the sweet herb (Brahmachari et al., 2011).

Steviosides are 100-300 times sweeter than sucrose (Abo Elnaga et al., 2016). Stevia is inexpensive and available to most consumers; thus, it has the potential to be widely used and may assist individuals in regulating their weight as it has a positive effect on caloric substitution (Anton et al., 2010). Also, steviosides have been used in many kinds of foods, beverages, medicine, cosmetics, household chemical industry and other food industries. Besides, non significant toxicity has been reported with stevia leaves extract administration (Abo Elnaga et al., 2016).

In addition, stevia has multipurpose medicinal uses. It is used for the treatment of various conditions such as diabetes, obesity, hypertension, fatigue and depression. It possesses hypotensive, vasodilatation, taste improving, sweetening, antifungal, antiviral, anti-inflammatory, antioxidant antibacterial properties and increases urination function of the body (Das and Kathiriya, 2012).

Furthermore, it has been found to have beneficial effects on blood glucose and insulin levels in human studies suggesting its role in food intake regulation with no reported side effects (Anton et al., 2010). 
There is evidence suggesting that there is no histological damage to hepatic cells under Stevia rebaudiana leaf extract supplementation indicating its protective effect against liver damage (Mohan and Robert, 2009).

So, the aim of the present study is to assess the histological and histochemical alterations in liver sections from rats administrating sucrose as a high caloric widely used sweetener.

In addition to compare the histological and histochemical variations in liver tissues from rats administrated aspartame (a synthetic sugar substitute) and stevia (a natural sugar substitute) for both short duration (30 days) and long duration (90 days).

\section{Material and Methods}

\subsection{Experimental Animals:}

The present study was conducted using male albino rats of the strain Rattus norvegicus. They weighted an average weight of $100 \pm 10 \mathrm{gm}$. They were housed in wire mesh laboratory animal cages in the vivarium of the Animal house of Medical Research and Bilharzia Center, Faculty of Medicine, Ain Shams University. All procedures have been performed in accordance with national animal welfare legislation of Faculty of Medicine, Ain Shams University.

\subsection{Experimental Chemicals and Dosage: A-Sucrose:}

Sucrose $\left(\mathrm{C}_{12} \mathrm{H}_{22} \mathrm{O}_{11}\right)$ is a disaccharide of molecular weight 342.20. Sucrose was administrated orally to rats as $10 \%$ sucrose solution dissolved in tap water (w/v). Sucrose was purchased from ADWIC (El-Nasr pharmaceutical chemicals Company Egypt). It was orally supplemented to rats for 90 consecutive days according to (Kendig et al., 2013). This sucrose solution provided a caloric density of approximately $(0.4 \mathrm{kcal} / \mathrm{g})$ similar to most commercially available sugar drinks.

\section{B- Aspartame:}

Aspartame (1-methyl N-L-a-aspartyl-L-phenylalanine) was purchased as tablet formulation from (Amrya for pharmaceutical industries Alexandria - Egypt). Each tablet contained $20 \mathrm{mg}$ of aspartame (one tablet equal to one teaspoonful of sugar and 0.4 calorie) .Tablets were dissolved in water and given orally to rats at a dose of $75 \mathrm{mg} / \mathrm{kg}$ body weight /day for 90 consecutive days according to (Ashok et al., 2013).

\section{C-Stevia:}

Stevia was purchased as a powder from Alpha Nexa Nutritionals Ltd, Kent (U.S.A.). It was dissolved in drinking water and given orally as the calculated human therapeutic dose according to Paget and Barnes, (1964) at a dose of $40 \mathrm{mg} / \mathrm{kg}$ body weight /day for 90 consecutive days.

\subsection{Experimental Design:}

In the present investigation a total number of 64 male albino rats were used. They were allowed a pre-experimental period of 5 days for acclimatization. Rats were divided into four groups. Every experimental group consisted of 16 rats. The first group served as control receiving 
tap water, the second group represented the sucrose group, the third group represented the aspartame group and the fourth group represented the stevia group. Rats were subjected to different experimental regimens for two durations, short duration (30 days) and long duration (90 days).

\subsection{Histological And Histochemical Methods:}

Liver organs from rats in all groups were carefully dissected. They were subsequently cut into small pieces. Parts of liver tissues were placed in $10 \%$ buffered formalin, dehydrated, cleared with xylene, infiltrated with paraffin wax at $60^{\circ} \mathrm{C}$ then embedded. Paraffin blocks were cut at 6 microns and affixed to slides then stained.

\subsubsection{Histological Investigations}

Liver sections were stained with Haematoxylin and Eosin (Bancroft and Cook, 1994) and Mallory's trichrome stain (Sweat et al., 1968) for general histological examination.

\subsubsection{Histochemical Investigations}

For the demonstration of particular histochemical features, the following staining techniques were employed:

I. Best's carmine technique (Best's, 1906) for the detection of glycogen.

II. Bromophenol blue (Mazai et al., 1953) for the demonstration of sites of total protein content.

III. Sudan Ш stain (Humason, 1979) for staining of triglycerides and lipoproteins on frozen paraffin sections.

Different histochemical features were analyzed quantitatively in the Regional center of Mycology and Biotechnology (Al-Azhar University) using image analyzer Unit Olympus BX40.

\subsection{Statistical Analysis}

Image analysis of liver sections stained by different histochemical stains was expressed as means \pm standard error of means (SE). All the recorded data were analyzed using the Statistical Processor System Support (SPSS) version 10 computer program. The significance of differences between means of the control and all treated rats (a) were analyzed using one-way analysis of variance (ANOVA) test.

\section{Results}

\subsection{Histological Investigation}

The histological picture of liver sections obtained from group of rats treated with sucrose for 30 days, manifested some lesions such as, hemorrhagic, inflammatory reaction and dilated portal tracts. Besides, signs of vascular degeneration and lymphoid aggregates were seen. Also vascular congestion was evident and the blood sinusoids were dilated compared with control Fig. (1-a) and (1-c).

Mild increase in collagenous fibers was evident compared with control (Fig. 1-b). This was realized commencing from the $30^{\text {th }}$ day post sucrose treatment and persisted till the end of 
experimentation with particular increase around central vein, portal tracts (Fig. 1-d) degenerative and necrotic areas.

Section of livers from animals receiving sucrose for 90 days realized fatty degeneration and necrotic nuclei. The cytoplasms of these degenerative cells were vacuolated and faintly stained, while a few number of nuclei showing early signs of pyknosis (Fig. 1-e). Dilated blood sinusoid was also a prominent feature. In addition mononuclear infiltration mainly lymphocytic in nature was marked and inflammatory cellular infiltration in addition to the presence of small number of Kupffer cells. Also, increase in collagen fibers that extended in different areas of the liver tissue was noticed. The increase of collagenous tissue was more obvious in intracellular space and necrotic areas (Fig.1-f).

Histological examination of liver of rats revealed great pathological deviations from normal pattern post aspartame treatment which lasted till the end of experimentation i.e.90 days. Histological liver changes were first manifested from the $30^{\text {th }}$ day post aspartame treatment; this was characterized by early degenerative changes in the hepatic parenchyma appearing with variable grades in different areas of the liver tissue. In addition, mild hemorrhages, foci of inflammatory infiltrative cells were realized surrounding dilated portal tracts, central vein and increased Kupffer cells. Dilatation and congestion of the blood vessels with demolished endothelial cells was apparent (Fig. 2-a). Also, increase in collagenous fibers was primarily apparent 30 days post aspartame administration (Fig. 2-b).

At the end of the study i.e. after 90 days of treatment with aspartame, liver sections showed variable histopathological changes: general loss of hepatic architecture, presence of multi nuclear cells and increased Kupffer cells. Lymphocytic accumulation could be seen around the engorged blood vessels. In addition, focal areas of necrosis were frequently encounted. In these necrotic areas, every parenchymal cell showed fragmentation or was undergoing discentigration resulting in abnormally shaped histological pattern (Fig. 2-c). On the other hands, collagenous fibers were speculated around portal tract, central vein sinusoids and branched into the surrounding hepatic tissue (Fig. 2-d). Moreover, the liver nuclei suffered severe karyolysis where nuclear membranes were realized shrunken and indistinct from the cytoplasm. The cytoplasm appeared as widespread areas of complete vaculations. The Kupffer cells were very active and within portal tracts there were increased numbers of chronic inflammatory cells. Besides, marked stagnation of blood was evidenced and persisted throughout the duration of the experiment.

The histopathological picture of the liver sections obtained from group of rats treated with stevia for 30 days manifested minimal changes in the structure of the liver compared to normal ones. This was characterized by dilated central vein and blood sinusoids. The majority of hepatic tissue appeared near to normal in configuration. The liver cells were arranged in the form of cords radiating from central vein to the periphery (Fig. 2-e).

Liver section from rats receiving stevia for 90 days showed that most areas of liver tissue appeared near to normal in hepatic pattern (Fig. 2-g).

Furthermore, liver sections manifested preserved collagenous fibers architecture after 30 and 90 days of stevia administration (Fig. 2-f) (Fig. 2-h). 

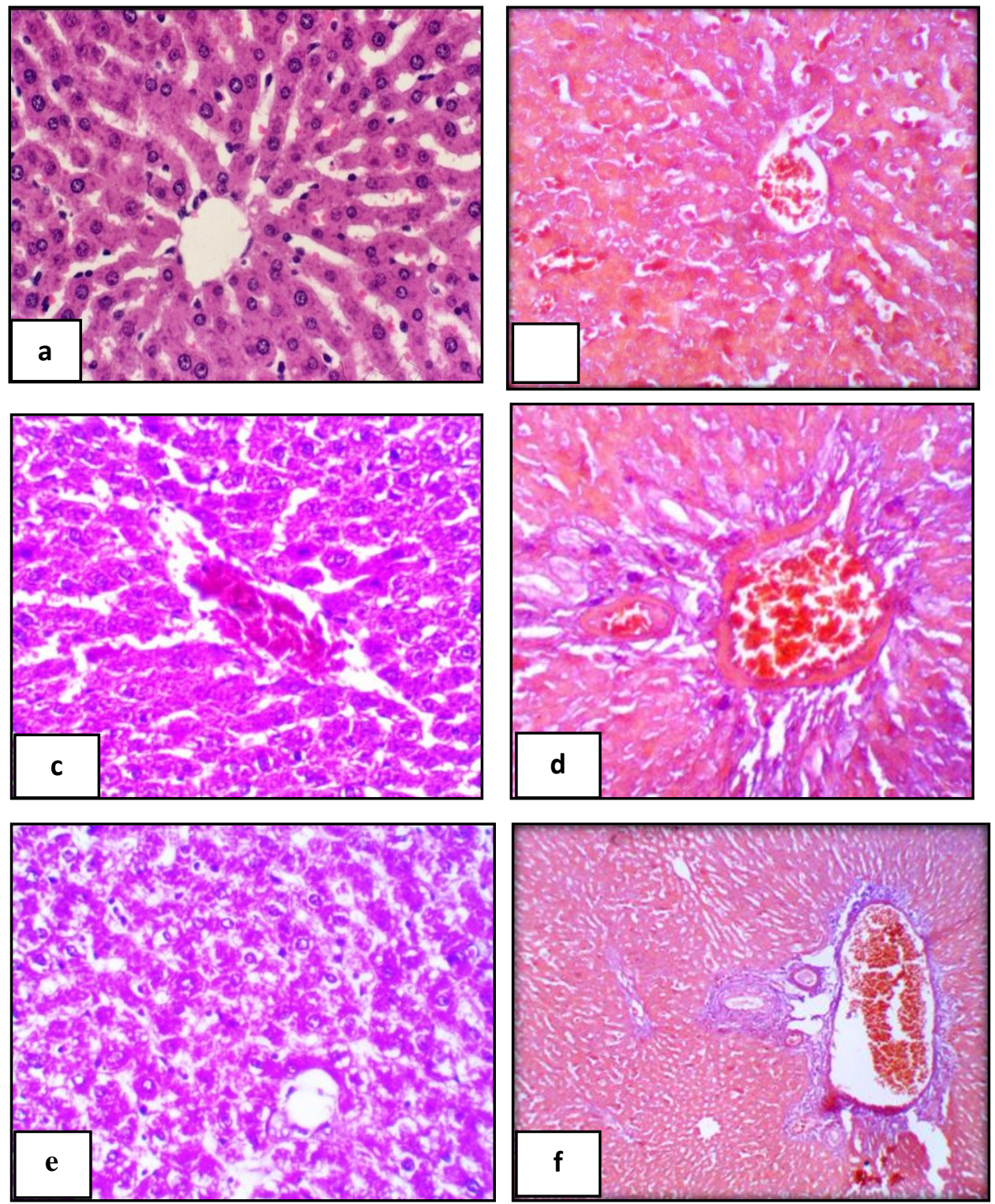

Fig. (1): Photomicrograph of liver section:

a) Control rat showing normal hepatic pattern of central vein, hepatocytes and blood sinusoids (Hx-E; x250).

b) Normal distribution of collagenous fibers (Masson's trichrome; x250).

c) After 30 days post treatment of sucrose showing dilated sinusoid (Hx-E; x250).

d) Sucrose rat group after 30 days showing mild increase in collagenous fibers with particular increase around central vein portal tracts degenerative and necrotic areas (Masson's trichrome; x250).

e) After 90 days post treatment of sucrose showing fatty degeneration of hepatocytes with pyknotic nuclei (Hx-E; x250).

f) Sucrose rat group after 90 days showing the increase of collagenous tissue in intracellular space and necrotic areas

(Masson's trichrome; $\mathbf{x 1 0 0 ) .}$ 

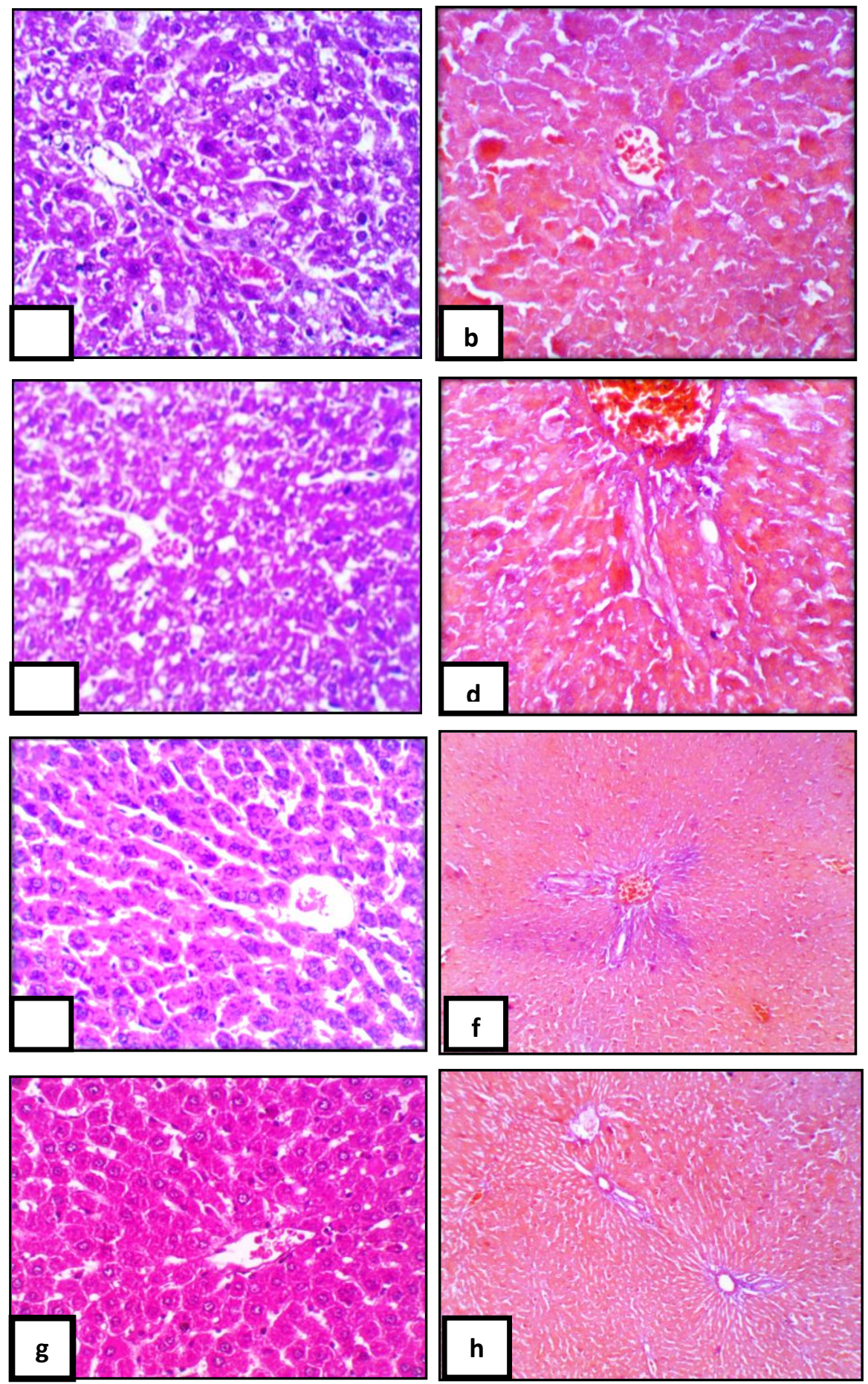

Fig. (2): Photomicrograph of liver section:

a) After 30 days post treatment of aspartame showing dilatation and congestion of blood vessels with demolished endothelial cells (HxE; $\mathbf{x 2 5 0 )}$.

b) Aspartame rat group after 30 days showing increase in collagenous fibers (Masson's trichrome; $\mathbf{x 2 5 0}$ ).

c) After 90 days post treatment of aspartame showing distortion of normal lobular architecture (Hx-E; x250).

d) Aspartame rat group after 90 days showing collagenous fibers speculated around portal tract, central vein sinusoids and branching into surrounding hepatic tissue (Masson's trichrome ;x250).

e) After 30 days post treatment of stevia showing liver cells arranged in the form of cords radiating from central vein to the periphery (Hx-E; x250).

f) Stevia rat group after 30 days showing increase in collagenous fibers surrounding the portal tract and blood vessels (Masson's trichrome; x100).

g) After 90 days post treatment of stevia showing liver tissue appearing near to its normal pattern (Hx-E; x250).

h) Stevia rat group after $\mathbf{9 0}$ days showing preserved collagenous fibers architecture (Masson's trichrome; x100). 


\subsection{Histochemical Investigation:}

\subsubsection{Glycogen Content:}

Glycogen stores in treated rats were significantly affected compared with control (Fig. 3a) and table (1). In liver sections from rats treated with sucrose, the glycogen granules in the hepatocytes were manifested to be depleted after 30 days post-treatment (Fig. 3-b). At the end of the study i.e. 90 days, glycogen stain was extremely fainted within the hepatocytes. Cytoplasm stainable material appeared as randomly dispersed fine deposits in most cells while other cells appeared wholly lacking glycogen (Fig. 3-c). Marked significant inhibition in glycogen was observed in liver sections from rats treated with aspartame. Centro lobular depletion of glycogen stores progressed peripherally in most of the hepatic lobules (Fig. 3-d). By the end of the experiment i.e. 90 days post-treatment, most hepatic cells were manifested devoid of glycogen (Fig. 3-e).

On the other hand, Best Carmine stains revealed non-significant alteration in group of rats treated with stevia either 30 or 90 days, where glycogen stores appeared patchy and heterogeneous in distribution among hepatic lobules (Fig. 3-f) (Fig. 3-g).

Table (1): Image analysis of glycogen stores after 30 and 90 days:

\begin{tabular}{|l|l|l|l|l|l|l|}
\hline Parameters & Duration & Groups & Control & Sucrose & Aspartame & Stevia \\
\hline $\begin{array}{c}\text { Glycogen } \\
\text { Absorbance }\end{array}$ & $\mathbf{3 0}$ days & Mean \pm SE & $124.80 \pm 0.29$ & $110.54^{* * * a} \pm 0.75$ & $104.62^{* * * a} \pm 1.11$ & $122.86 \pm 0.64$ \\
\cline { 2 - 7 } & $\mathbf{9 0}$ days & Mean \pm SE & $125.83 \pm 0.52$ & $103.99^{* * * a} \pm 1.40$ & $92.94^{* * * a} \pm 2.63$ & $121.81 \pm 0.58$ \\
\hline
\end{tabular}

${ }^{a}$ All experimental groups compared with the control group. Values are expressed as mean \pm SE compared with the control group; * significant; ** highly significant, *** very highly significant.

\subsubsection{Protein Content:}

Histochemical staining of liver sections stained with bromophenol blue for the demonstration of total protein content in rats receiving sucrose for 30 days revealed gradual decrease in the protein content compared with control (Fig. 4-a) and (Fig. 4-b). This decrease commenced from the first day of treatment and persisted until the end of the study where many of the hepatocytes lacked their protein content at 90 days of sucrose treatment (Fig. 4-c).

In addition, liver sections of rats receiving aspartame for 30 days manifested gradual decrease in the protein content. This was confined to several cells that showed moderate staining affinity by 30 days (Fig. 4-d). This decrease persisted until the end of the study i.e. 90 days. It was followed by high attenuation in the staining affinity where most of the hepatocytes lacked their protein content by the 90 days of treatment. Pyknotic cells appeared with dark nuclear staining while cytoplasm was completely faint in staining affinity (Fig. 4-e). 
Liver sections of experimental animals treated with stevia stained with bromophenol blue for detecting protein content manifested minimal variations in the protein content after the first day i.e. 30 days of treatment (Fig. 4-f). By the end of 90 days post-treatment slight decreased protein content was detected in hepatic tissue (Fig.4-g).

Applying the bromophenol blue technique, total protein content distribution in cell cytoplasm and nucleus is demonstrated in (table 2).

Table (2): Image analysis of protein after 30 and 90 days:

\begin{tabular}{|c|c|c|c|c|c|c|}
\hline Parameters & Duration & Groups & Control & Sucrose & Aspartame & Stevia \\
\hline \multirow{2}{*}{$\begin{array}{c}\text { Protein } \\
\text { absorbance }\end{array}$} & $\mathbf{3 0}$ days & Mean \pm SE & $123.90 \pm 0.78$ & $107.29^{* * * a} \pm 0.655$ & $88.33^{* * * a} \pm 0.58$ & $122.29 \pm 0.43$ \\
\cline { 2 - 7 } & $\mathbf{9 0}$ days & Mean \pm SE & $124.90 \pm 0.64$ & $101.85^{* * * a} \pm 0.90$ & $72.53^{* * * a} \pm 1.34$ & $122.85 \pm 0.54$ \\
\hline
\end{tabular}

${ }^{a}$ All experimental groups compared with the control group. Values are expressed as mean \pm SE compared with the control group; * significant; ** highly significant, *** very highly significant.

\subsubsection{Fat Content:}

Fat is deposited in the cytoplasm of hepatic cells of control liver sections. It always appears first in cells adjacent to central veins of lobules. Also, few mesenchymal cells that are fat storing are present within the perisinusoidal spaces (Fig. 5-a).

On the other hand, in liver sections of rats consuming sucrose for 30 days, marked increase in the fatty deposition in the hepatic tissue (fatty infiltration) was obvious (Fig. 5-b). This was demonstrated in the form of heavy deposits of fats particularly demonstrated in periportal areas (Fig. 5-c).

Also, significant increase in fatty deposition in the hepatic tissue started from the fourth weeks post treatment in group of animal treated with aspartame for 30 days (Fig.5-d) and persisted until the end of experiment time i.e. 90 days. Fat deposits appeared in both the globular and granular forms. Increased fat-deposition coincided with degenerative and necrotic foci (Fig. 5-e).

In frozen sections of rats administrated stevia for 30 and 90 days, the fatty deposition in the hepatic tissues showed non significant changes when compared with the control ones (Fig. 5f) and (Fig. 5-g). Data of liver sections stained with Sudan Ш of both control and experimental groups are presented in table (3). 
Table (3): Image analysis of fat deposits after 30 and 90 days:

\begin{tabular}{|c|l|l|l|l|l|l|}
\hline Parameters & Duration & Groups & Control & Sucrose & Aspartame & Stevia \\
\hline \multirow{2}{*}{$\begin{array}{c}\text { Fat } \\
\text { absorbance }\end{array}$} & 30 days & Mean \pm SE & $102.21 \pm 0.87$ & $110.98^{* * * a} \pm 0.54$ & $115.00^{* * * a} \pm 0.48$ & $100.53 \pm 0.68$ \\
\cline { 2 - 7 } & 90 days & Mean \pm SE & $103.74 \pm 0.77$ & $115.44^{* * * a} \pm 0.96$ & $120.60^{* * * a} \pm 1.28$ & $102.02 \pm 1.15$ \\
\hline
\end{tabular}

${ }^{a}$ All experimental groups compared with the control group. Values are expressed as mean $\pm \mathrm{SE}$ compared with the control group; * significant; ** highly significant, *** very highly significant.
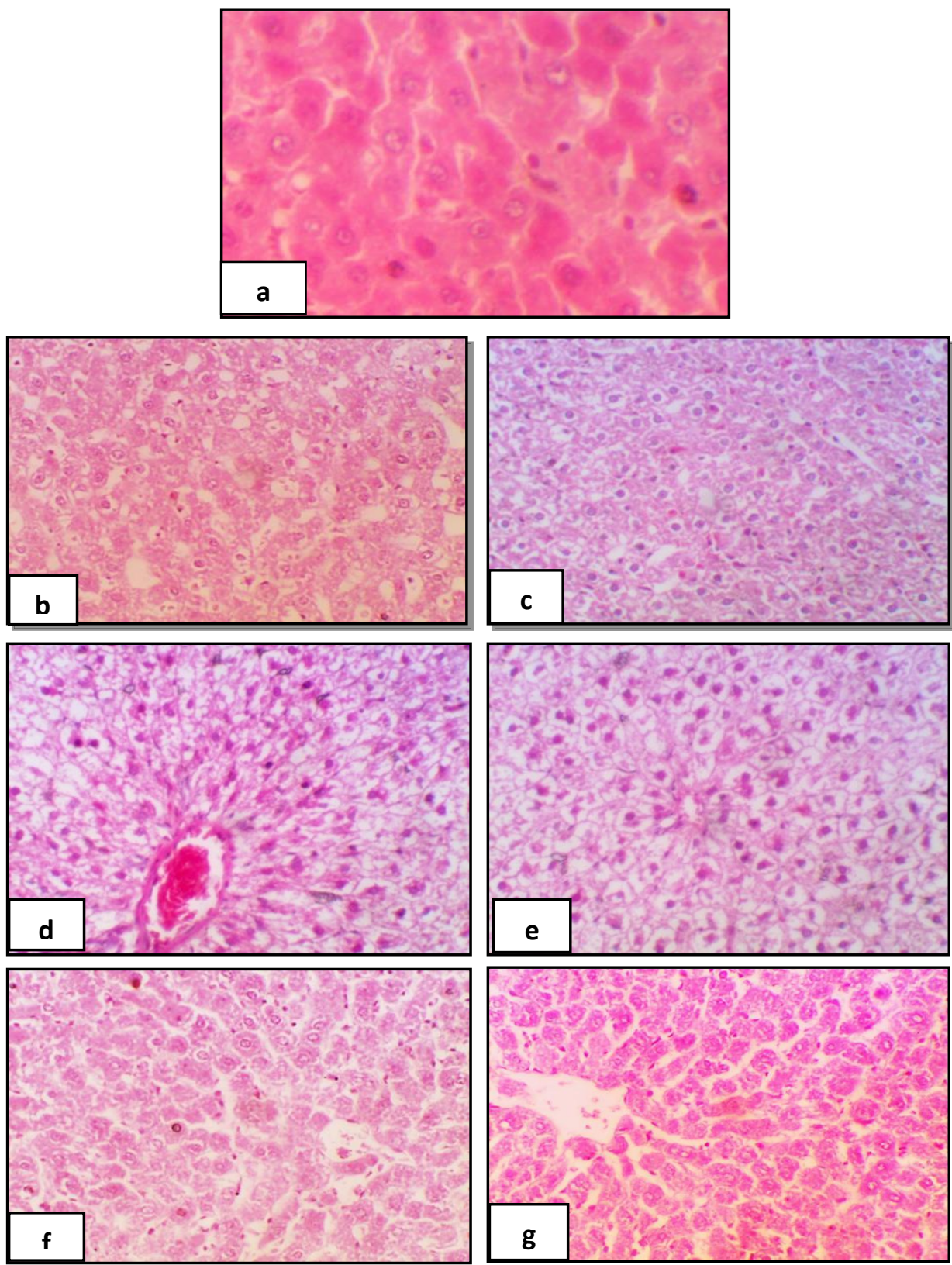
Fig. (3): Photomicrograph of liver section:

a) Control rat group showing normal distribution of glycogen within hepatocytes (Best Carmine; $\mathbf{x} 250$ )

b) Rats receiving sucrose after 30 days showing depletion in glycogen granules (Best Carmine; $\mathbf{x} 250$ ).

c) Rats receiving sucrose after 90 days showing randomly dispersed fine deposit in some hepatocytes while other cells appeared wholly lacking glycogen (Best Carmine; x 250).

d) Rats receiving aspartame after 30 days showing depletion of glycogen content in the periphery of the hepatic lobules (Best Carmine; $\mathbf{x}$ 250).

e) Rats receiving aspartame after 90 days showing hepatocytes devoid of glycogen (Best Carmine; x 250).

f) Rats receiving stevia after 30 days showing mild deposit of glycogen in most liver tissue (Best Carmine; $\mathbf{x} 250$ ).

g) Rats receiving stevia after 90 days showing more or less normal distribution of glycogen in most hepatic cells (Best Carmine; x 250).
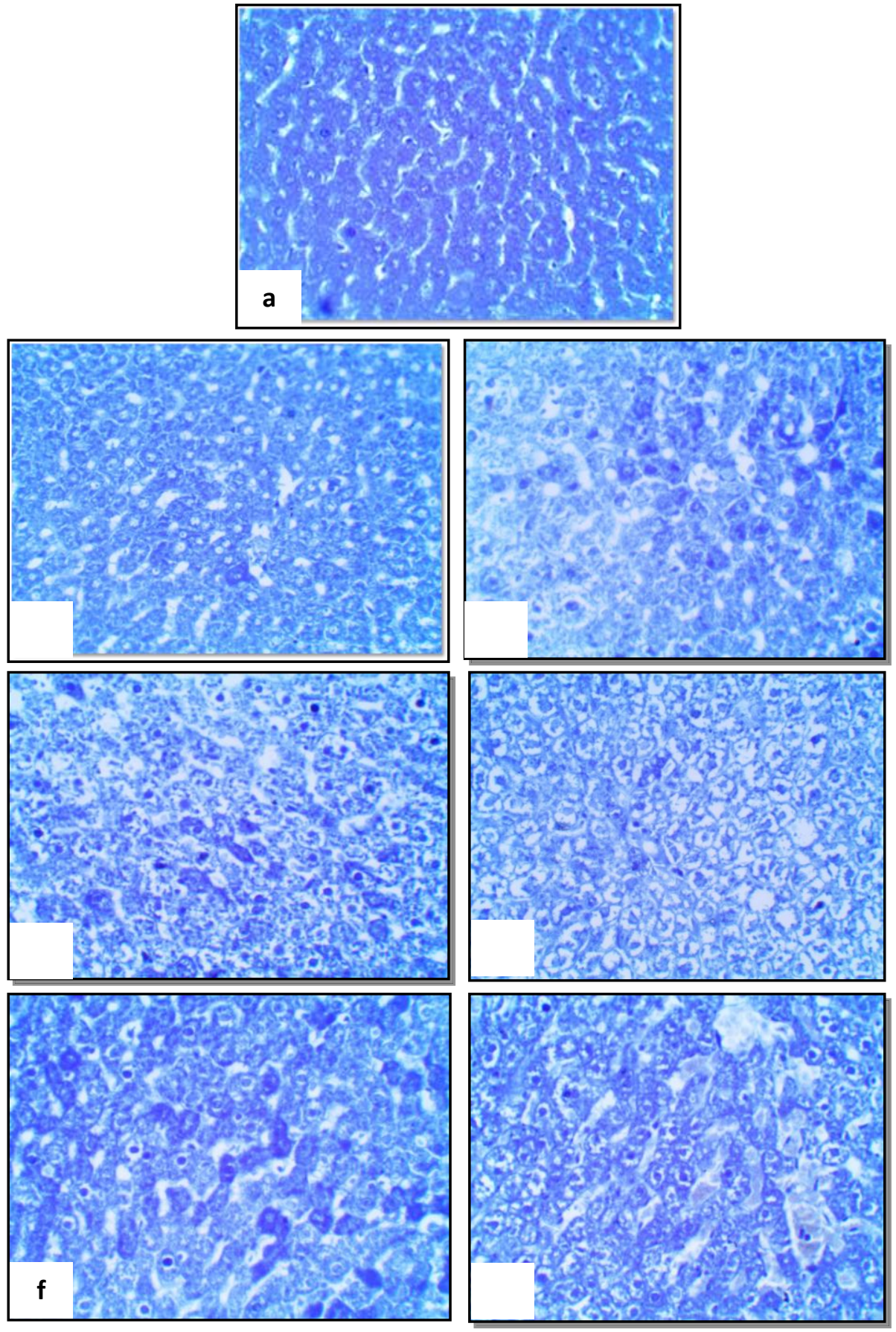
Fig. (4): Photomicrograph of liver section:

a) Control rat showing normal distribution of protein in cytoplasm and nucleus in hepatocytes (Bromophenol blue; $\mathbf{x} 250$ ).

b) Rat receiving sucrose for 30 days showing mild decrease in protein content of hepatocytes (Bromophenol blue; $\mathbf{x} 250$ )

c) Rat receiving sucrose for 90 days showing many hepatocytes lacking their protein content (Bromophenol blue; $\mathbf{x} 250$ ).

d) Rat receiving aspartame for 30 days showing moderate staining of protein content (Bromophenol blue; $\mathbf{x} 250$ ).

e) Rat receiving aspartame for 90 days showing dark nuclear staining protein in pyknotic cells and completely faint in the cytoplasm (Bromophenol blue; $x$ 250).

f) Rat receiving stevia after 30 days showing mild decrease in the protein content (Bromophenol blue; $\mathbf{x} 250$ ).

g) Rat receiving stevia after 90 days showing the protein content was slightly decrease in hepatic tissue (Bromophenol blue; $\mathbf{x} 250$ ).
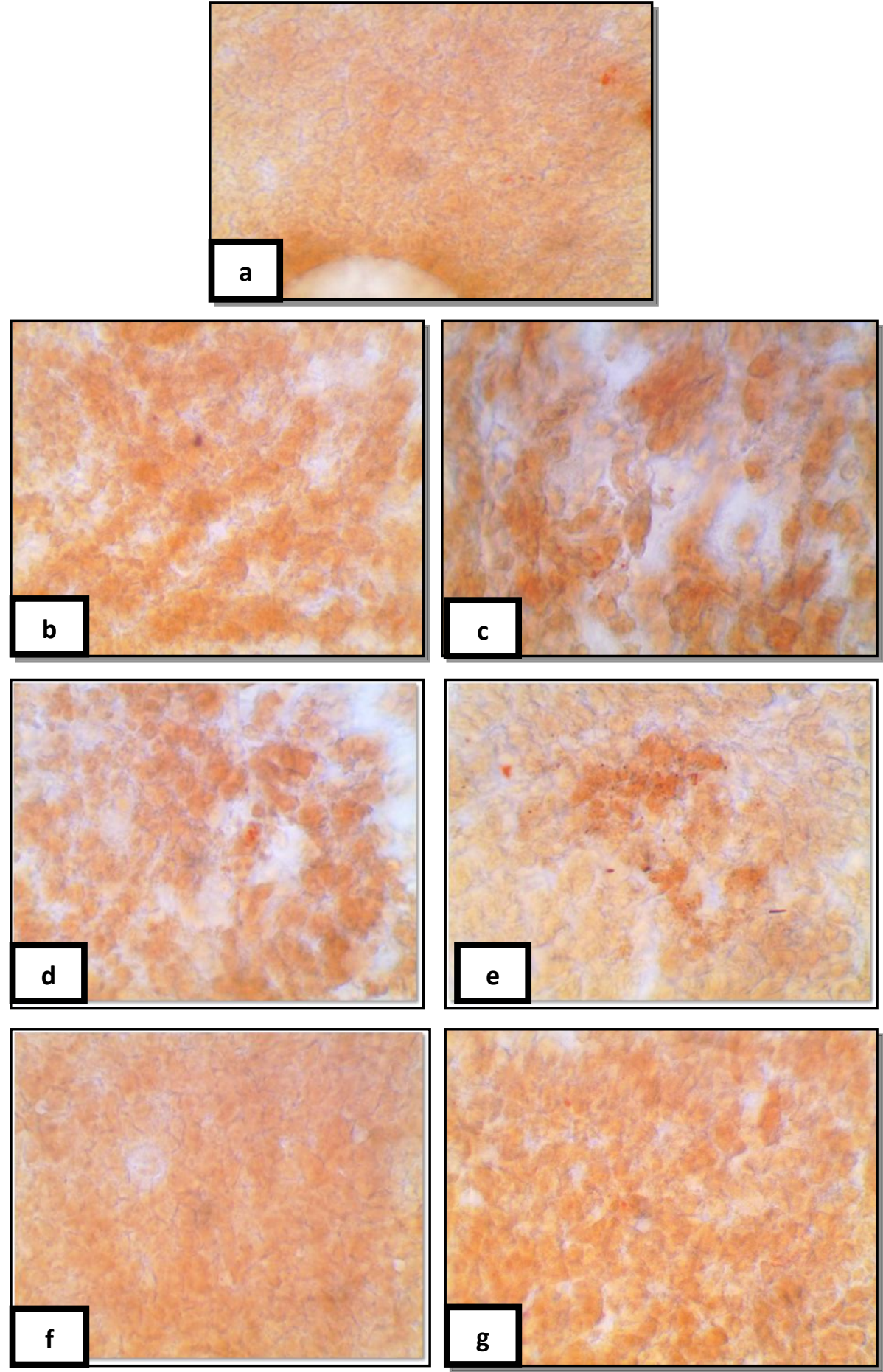
Fig. (5): Photomicrograph of frozen liver section:

a) Control rat group showing normal distribution of fat content in the hepatocytes (Sudan II; x 400).

b) Rats receiving sucrose for 30 days showing mild increase in fatty deposition in the hepatic tissue (Sudan $\mathbf{I}$; $\mathbf{x} 400$ ).

c) Rats receiving sucrose for 90 days showing heavy deposits of fats (Sudan III; $\mathbf{x} 400$ ).

d) Rats receiving aspartame for 30 days showing globular and granular fat deposits in hepatocytes (Sudan $\mathbf{~} \mathbf{x}$ (400).

e) Rats receiving aspartame for 90 days showing increased fat deposition in the hepatocytes (degenerative and necrotic foci) (Sudan III; $\mathbf{x}$ 400).

f) Rats receiving stevia for 30 days showing decreased fat deposition in the hepatic tissue (Sudan II; x 400).

g) Rats receiving stevia for 90 days showing fat deposits near to normal hepatic tissue (Sudan Ш; x 400).

\section{Discussion}

This study was conducted to compare aspartame as a synthetic non caloric sweetener and stevia as a natural non caloric sweetener with sucrose as a generically used sweetener. This comparative work was based on studying alterations in the histological and histochemical features of liver tissue. Oral sucrose administration at a dosage of $5 \mathrm{mg} / \mathrm{kg}$ body weight /day to rats for 90 consecutive days manifested dilated blood sinusoids with blood stagnation. In addition, mononuclear infiltration mainly lymphocytic was also observed.

The histological findings present here in this investigation were supported by (Morsy et al., 2014) who proved that hepatocytes of rats administrating sucrose diet showed infiltration by dark inflammatory cells with shrunken pyknotic nuclei, dilated central veins and discontinuity of endothelial cells of the blood sinusoids that was filled with excessive bleeding. The hepatic sinusoids showed severe bleeding with discontinuity of its endothelial lining and the nuclei appeared severely swollen with segregated nucleolus and irregular nuclear membrane. Also, the hepatocytes were severely destroyed with loss of cellular landmarks and loss of their architectures under high sucrose diet. This may be due to the increased amounts of daily sucrose intake which was associated with more and more hepatic tissue injuries and liver function deterioration.

Sweetening beverages with sucrose is associated with increasing rates of obesity and diabetes because sucrose influences lipid metabolism causing hepatic injuries produced not only at the metabolic level, but also at the ultra-structural hepatic tissue changes. Consuming sucrosesweetened beverages increased triglyceride synthesis and deposition, and can cause fatty liver in rats (Ackermanz. et al., 2005). This supports the histological findings of fatty degeneration of hepatocytes with pyknotic nuclei present here in this study under 90 days of sucrose administration. Again sucrose administration stimulates insulin resistance producing inflammation in liver tissue thus activating inflammatory cytokines as tumor necrosis factor alpha and interleukin-6 (Hotamisligil, 2006).

The histopathological examination of collagenous fibers of the liver tissue elucidated mild increase in collagenous fibers after 30 and 90 days of sucrose administration. This extended in different areas of the liver tissue and was more obvious in intra cellular space and necrotic areas. This may be due to the collagen fibers infiltration inside hepatic tissue (Bray, 2013). 
Furthermore, (Villalobos et al., 2015) verified that animals with the high sucrose diet developed insulin resistance. Insulin resistance plays an important role in the development of non-alcoholic fatty liver disease. The development of fatty liver is influenced by the increase in de novo synthesis of free fatty acids by the liver and decrease in the antilipolytic effect (Vanni et al., 2010). This was clearly confirmed by the depletion of glycogen granules in hepatocytes stained by Best carmine stain after 90 days of sucrose administration.

The results of the present study showed a decrease in the protein content in hepatocytes stained with Bromophenol blue stain. These results were in accordance with (Prokić et al., 2015) that ratified a significant decline in the total protein under sucrose administration to rats for 30 and 90 days.

Moreover, the histopathological stained liver sections with Sudan Ш demonstrating the fat content of hepatocytes elucidated swollen hepatocytes with excessive lipid droplets in the cytoplasm and severe cellular fat vacuolation in the liver tissue which reflects the marked increase in the fatty deposition in hepatic tissue and in periportal areas under long term sucrose administration (Morsy, et al., 2014).

In addition to the previous explanations, histopathological and histochemical examination of hepatic tissue in the present study supported our claims that increasing daily dietary sucrose deteriorates the glucostate and the serum lipids that are reflecting on the hepatic functions (Hotamisligil, 2006).

Presently, the histological findings of liver sections from rats receiving aspartame at a dose of $75 \mathrm{mg} / \mathrm{kg}$ for 90 days displayed obvious histological changes, in the form of cytoplasmic vacuoles in hepatocytes, disorganized hepatic parenchyma, congestion of the central vein and hepatic sinusoids, mononuclear cell infiltration in aspartame treated groups (Abhilash et al., 2011; El Haliem and Mohamed, 2011 and Abd El fatah et al., 2012).

The histological finding of liver tissue of rats administrating aspartame for 90 days identifies hepatocyte damage, recruitment and activation of inflammatory cells as macrophages, eosinophil and neutrophils. These histological alterations may be due to the release of inflammatory and fibrogenic cytokines, production of reactive oxygen species; activation of hepatic stellate cells, periportal or perivenular fibroblasts, circulating fibrocytes and bone marrow cells that trans differentiate into collagen producing myofibroblats (Yao et al., 2012 and Zhong et al., 2013). This is indicative of cellular leakage and loss of functional integrity of liver.

Aspartame is completely hydrolyzed in the gastrointestinal tract to aspartic acid, phenylalanine and methanol, each being toxic at high levels. These findings may help us to understand that cumulative daily intake dose of aspartame led to an increase of blood methanol concentration above the individual baseline values (Španěl et al., 2015). Methanol is primarily metabolized by oxidation to formaldehyde and then to formate (Abhilash et al., 2015).

Again, formaldehyde causes histological changes supported by the damage of liver cells which might be secondary to the activation of Kupffer cells that secrete tumor necrosis factor alpha, interleukins, reactive oxygen, nitrogen species, proteases, and prostaglandins. These mediators could act directly on hepatocytes to cause cell death (El Haliem and Mohamed, 2011). 
Also, these aspartame metabolites causes the formation and release of many inflammatory mediators thereby recruiting neutrophils, lymphocytes, and other inflammatory cells into damaged regions (Alleva et al., 2011).

Furthermore, oxidation of methanol, a metabolite of aspartame can be followed by a release of leukotriene's, resulting in poly morphonuclear leukocyte infiltration of the liver, presumably associated with an oxidative burst and production of reactive oxygen mediators. Reactive oxygen species may stimulate the release and formation of various inflammatory chemokines. Chemokines are involved in the migration of leukocytes into the liver during aspartame intoxication .Chronic aspartame intoxication selectively enhanced chemokine released by Kupfer cells and hepatic sinusoidal cells and migration of inflammatory cells to liver. The up regulated expression of different members of the chemokine system is likely to result in leukocyte infiltration (Abhilash et al., 2011). This idea supports the results of the present study which shows foci of inflammatory infiltrative cells surrounding dilated portal tracts and central vein and increase Kupfer cells under aspartame supplementation.

Again, the enhanced permeability of liver cells leads to damage or necrosis of hepatocytes. Similar results were reported by (Abdel-Salam et al., 2012).

In addition, hepatocytes damage triggers activation of TGF- $\beta 1$ which was produced by hepatic stellate cells and Kupffer cells that was believed to be involved in the synthesis and deposition of extracellular matrix components like fibronectin, collagens type I, III, and IV. TGF$\beta 1$ had a dual impact on the progression of liver disease by promoting fibrogenesis and inducing hepatocytes apoptosis (Bai et al., 2013).

The degenerative changes in liver tissue of aspartame group were clearer in the peripheral and intermediate zones of hepatic lobules than that of the central lobular zone (El-Sakhawy et al., 2015) because the hepatocytes in the peripheral zone were the first to receive oxygen, nutrients and toxins of aspartame metabolites from the sinusoidal blood (Stevens and Lowe, 2005 and Ross and Pawlina, 2011).

The present investigation displayed the heterogenous distribution of glycogen with depletion of glycogen stores in hepatic tissue in rats treated with aspartame for 90 days. The significant decrease in cytoplasmic glycogen inclusions in hepatocytes of rats may be due to the deleterious effects of aspartame on liver mitochondria (EI-Sakhawy et al., 2015).

Gradual decrease in the protein content in liver tissue of rats administrating aspartame for 90 days may be due to the accumulated formaldehyde (a metabolite of aspartame) which caused the prominent appearance of Von-Kupffer cells in some hepatic lobules. This in turn led to damage of protein molecules (El Haliem and Mohamed, 2011).

On the other hand, a significant increase in fat deposition in globular and granular forms appeared. This disturbed fat metabolism is closely related to insulin resistance that causes lipolysis and increases the circulating free fatty acids. These fatty acids are then taken up by the liver as an energy source. It is also suggested that there is an imbalanced systemic and hepatic fat metabolism with excess uptake and synthesis of fatty acids by the liver (Elattar et al., 2016). 
Presently, oral administration of stevia at a dose of (40 mg/kg body weight /day) for 30 and 90 days produced few swollen hepatocytes with foamy cytoplasm. Hepatic tissue of stevia treated rats showed near to normal hepatic architecture with preserved normal distribution of collagenous fibers.

In agreement with our findings (Abo Elnaga et al., 2016) proposed that rats treated with stevia sweetener demonstrated normal liver appearance with no fibrosis, mild inflammation and normal hepatic cells with well-preserved cytoplasm, nucleus and nucleolus and central vein. This study further supports the idea that the long term consumption of stevia sweetener solution did not produce any histologically observable hepatic steatosis, inflammation, or fibrosis. In addition, stevia has a little effect on hepatic morphology or development of overt liver damage (Figlewicz et al., 2009).

Additionally, (Das and Kathiriya, 2012) elucidated that liver sections of the animals treated with aqueous leaves extract of Stevia rebaudiana showed dose-dependent reduction of necrosis and revealed hepato-protective activity. The hepato-protective action of Stevia rebaudiana might be due to the presence of antioxidants like flavonoids and phenolic compounds .The decreased necrotic area by stevia extract as well as decrease in the infiltration of the inflammatory cells in the liver lobules is indicative of therapeutic efficacy of the stevia extract.

Besides, the hepato-protective effect of stevia is acted by antioxidative, anti-lipid peroxidative, anti-fibrotic, anti-inflammatory, membrane stabilizing, immunomodulatory and liver regenerating mechanisms posed by stevia extract (Chlopcikova et al., 2004 and Pradhan and Griish, 2006). The anti-inflammatory effect of stevia extract includes inhibition of neutrophil migration and inhibition of Kupffer cells (Amin et al., 2010). This confirms normality in Kupffer cells present in liver sections of rats treated with stevia.

These data were clearly confirmed by examination of collagenous fibers that showed significant improvement in collagen synthesis upon administration of stevia extract when compared to aspartame treated animals. This was probably due to the inhibitory effect of stevia extract on hepatic stellate cell activation (Wang et al., 2012).

Moreover, stevia administration signified an increase in glycogen stores and protein content among hepatic lobules. These results suggest that stevia extract modulated the oxidantantioxidant balance thus restoring glycogen and protein content in hepatic tissue (Mohan and Robert, 2009).

Sudan Ш staining revealed no hepatic steatosis in any of the animals treated with stevia. There was preserved hepatic architecture in all animals with no significant inflammatory infiltrates and no fibrosis (Figlewicz et al., 2009).

\section{Conclusion}

In conclusion, the aqueous extract of Stevia rebaudiana may have the potential to be used as a natural sweetener alternative to the synthetic sweetener aspartame. Stevia could be used as an accessible source of natural antioxidants with resultant health benefits. 


\section{References}

- Abd El-fatah, A.A.; Ghaly, I.S. and Hanafy, S.M.: Cytotoxic effect of aspartame (diet sweet) on the histological and genetic structures of female albino rats and their offspring. Pak. J. Biol. Sci.,15: 904-918 (2012).

- Abd Elwahab, A.H.; Yousuf, A.F.; Ramadan, B.K. and Elimam H.: Comparative effects of Stevia rebaudiana and aspartame on hepato-renal function of diabetic rats: biochemical and histological approaches. J.A.P.S., 7 (08): 034-042 (2017).

- Abdel-Salam, O.M.E.; Salem, N.A. and Hussein, J.S.: Effect of Aspartame on oxidative stress and monoamine neurotransmitter levels in lipopolysaccharide-treated mice. Neuro. Toxicol. Res., 21:245-255 (2012).

- Abhilash, M.; Sauganth, P.M.V.; Varghese, M.V. and Nair, R.H.: Effect of long term intake of aspartame on antioxidant defense status in liver. Food Chem. Toxicol., 49: 1203-1207 (2011).

- Abhilash, M.; Varghese, M.V.; Paul, M.S.; Alex, M. and Nair, R.H.: Effect of longterm intake of aspartame on serum biochemical parameters and erythrocyte oxidative stress biomarkers in rats. Comp. Clin. Path., 24(4): 927-933 (2015).

- Abo Elnaga, N.I.E.; Massoud, M.I.; Yousef, M.I. and Mohamed, H.H.A.: Effect of stevia sweetener consumption as non-caloric sweetening on body weight gain and biochemical's parameters in overweight female rats. A. O. A. S., 61(1):155-163 (2016).

- Ackerman, Z.; Oron-Herman, M.; Grozovski, M.; Rosenthal, T.; Pappo, O.; Link, G. and SELA, B.A.: Fructose-induced fatty liver disease: Hepatic effects of blood pressure and plasma triglyceride reduction. J. Hypertens., 45: 1012-1018 (2005).

- Adegoke, O. A.; Bamigbowu, E. O.; Braide, A. S. and Enyaosa, L. A.: Total protein and albumins concentrations in albino rats (Rattus norvegicus) fed granulated sugar and gari. I.J.A.B.R., 4(1\&2): 87 - 94 (2012).

- Alkafafy, M.; Ibrahim, Z.; Ahmed, M., and El-Shazly, S.: Impact of aspartame and saccharin on the rat liver: Biochemical, molecular and histological approach. Int. J. Immunopathol. Pharmacol., 1:1-9 (2015).

- Alleva, R.; Borghi, B.; Santarelli, L.; Strafella, E.; Carbonari, D.; Bracci, M. and Tomasetti, M.: In vitro effect of aspartame in angiogenesis induction. Toxicol. in vitro, 25(1): 286-293 (2011).

- Amin, A.M.; Kazem, A.H.; Hassan, S.M.; Youssef, E.A. and Khalil, E.M.: Effect of silymarin on liver injury induced by carbon tetrachloride in rats: Histo-pathological and Immuno-histochemical Studies. Egypt. J. Exp. Biol., 6(1): 107-115 (2010).

- Anton, S.D., Martin, C.K.; Han, H.; Coulon, S.; Cefalu, W.T.; Geiselman, P. and Williamson D. A.: Effects of stevia, aspartame, and sucrose on food intake, satiety, and postprandial glucose and insulin levels. Appetite, 55: 37-43(2010).

- Ashok, I. and Sheeladevi, R.: Oxidant stress evoked damage in rat hepatocyte leading to triggered nitric oxide synthase (NOS) levels on long term consumption of aspartame. J. Food drug. Anal., 23: 679 -691(2015).

- Ashok, I.; Wankhar, D.; Sheeladevi, R. and Wankhar, W.: Long-term effect of aspartame on the liver antioxidant status and histopathology in wistar albino rats. Biomed. Prev. Nutr., 190: 1-7(2013). 
- Bai, T.; Lian, L.H.; Wu, Y.L.; Wan, Y. and Nan, J.X.: Thymoquinone attenuates liver fibrosis via PI3K and TLR4 signaling pathways in activated hepatic stellate cells. Int. Immunopharmacol., 15: 275-81 (2013).

- Bancroft, J.D. and Cook, H.C.: Manual of Histological Techniques and their Diagnostic Application. 2nd ed. Edinburgh: Churchill Livingstone, 23-26(1994).

- Best, F.: Carmine staining of glycogen and nuclei. Z.wiss. Mikrosk., 23: 319-322(1906).

- Bizeau, M.E. and Pagliassotti, M.J.: Hepatic adaptations to sucrose and Fructose. Metabol., 54(9): 1189-1201(2005).

- Brahmachari, G.; Mandal, L.C.; Roy, Rajeev, Mondal, S. and Brahmachari, A.K.: Stevioside and related compounds molecules of pharmaceutical promise: a critical overview. Arch. Pharm. Chem. Life Sci., 344: 5-19(2011).

- Bray, G.A.: Energy and fructose from beverages sweetened with sugar or high-fructose corn syrup pose a health risk for some people. Adv. Nutr., 4 (2): 220-225 (2013).

- Chlopcikova, S.; Psotova, J.; Miketova, P. and Simanek, V.: Chemoprotective effect of plant phenolics against anthracyclin-induced toxicity on rats cardiomyocytes Part I. Silymarin and its flavonolignans. Phytother. Res., 18: 107-110 (2004).

- Das, K. and Kathiriya, A.K.: Hepatoprotective activity of stevia rebaudiana Bertoni leaves against thioacetamide induced toxicity. Turk. J. Pharm. Sci., 9(3): 343-352 (2012).

- Elattar, S.; Estaphan, S.; Mohamed, E.A.; El-zainy, A. and Naguib, M.: The protective effect of 1alpha, 25-dihydroxyvitamin d3 and metformin on liver in type 2 diabetic rats. J. Steroid Biochem. Mol. Biol., 173: 235-244 (2016).

- Elfhag, K.; Tynelius, P. and Rasmussen, F.: Sugar-sweetened and artificially sweetened soft drinks in association to restrained, external and emotional eating. Physiol. Behav., 91(2-3):191-195(2007).

- El-Haliem, N. and Mohamed, D.: The effect of aspartame on the histological structure of the liver and renal cortex of adult male albino rat and the possible protective effect of Pimpinellaanisum oil. Egypt J. Histol., 34: 715-726 (2011).

- EL-Sakhawy, M.; Elsaeed, O.M.; Hussein, SH. and EL-Shammaa, M.: Histological, histochemical and immunohistochemical evaluation of long term administration of aspartame on the liver of male albino rats. International conference of risk assessment application in food matrix and feed and its impact on human and animal health.1-11 (2015).

- Figlewicz, D.P.; Ioannou, G.; Bennett Jay, J.; Kittleson, S.; Savard, C. and Roth, C.L.: Effect of moderate intake of sweeteners on metabolic health in the rat. Physiol. Behav., 98: 618-624 (2009).

- Hotamisligil, G.S.: Inflammation and metabolic disorders. Nature, 444: 860-867 (2006).

- Humason, G.L.: Animal tissue techniques. $4^{\text {th }}$ ed.WH free man and company. SanFrancisco, USA (1979).

- Johnson, R.J.; Segal, M.S.; Sautin, Y.; Nakagawa, T.; Feig, D.I.; Kang, D.H., et al.: Potential role of sugar (fructose) in the epidemic of hypertension, obesity and the metabolic syndrome, diabetes, kidney disease, and cardiovascular disease . Am. J. Clin. Nutr., 86: 899-906 (2007).

- Kendig, M.D.; Boakes, R.A.; Rooney, K.B. and Corbit, L.H.: Chronic restricted access to $10 \%$ sucrose solution in adolescent and young adult rats impairs spatial memory and alters sensitivity to outcome devaluation. Physiol. Behav., 120: 164-172 (2013). 
- Lemus-Mondaca, R.; Vega-Galvez, A.; Zura-Bravo, L. and Ah-Hen, K.: Stevia rebaudiana Bertoni, source of a high-potency natural sweetener: a comprehensive review on the biochemical, nutritional and functional aspects. Food Chem., 132: 1121-1132 (2012).

- Marinovich, M.; Galli, C.L.; Bosetti, C.; Gallus, S. and La Vecchia, C.: Aspartame, low-calorie sweeteners and disease: Regulatory safety and epidemiological issues. Food Chem. Toxicol., 60: 109-115(2013).

- Mazai, D.; Brewe, P.A. and Affert, M.: The cytochemical staining and measurement of protein with mercuric bromophenol blue. J. Biol. Bull., 104: 57-64 (1953).

- Mohan, K. and Robert, J.: Hepatoprotective effects of Stevia rebaudiana Bertoni leaf extract in CCl4-induced liver injury in albino rats. Med. Arom. Plant Sci. Biotec., 3(1):59-61(2009).

- Morsy, M.D.; Abdel-Razek, H.A.; Eid, R.A. and Hassab EL-Naby, W.M.: Impact of different doses of sucrose on the liver function and ultrastructure in rats. Med. J. Cairo Univ., 82:133-144 (2014).

- Mourad, I.: Effect of aspartame on some oxidative stress parameters in liver and kidney of rats. Afr. J. Pharm. Pharmacol., 5(6): 678-682(2011).

- Paget, G.E. and Barnes, J.M.: Toxicity tests. In: Laurence DR, Bacharach AL (ed.) Evaluation of drug activities. Pharmacometrics (p 161) .London: Academic Press (1964).

- Portela, G.S.; Azoubel, R. and Batigalia, F.: Effects of aspartame on maternal-fetal and placental weights, length of umbilical cord and fetal liver: A kariometric experimental study. Int. J. Morphol., 25(3): 549-554(2007).

- Pradhan, S.C. and Griish, C.: Hepatoprotective herbal drug, silymarin from experimental pharmacology to clinical medicine. Indian J. Med. Res., 124: 491-504 (2006).

- Prokić, M.D.; Paunović, M.G.; Matić, M.M.; Đorđević, N.Z.; Ognjanović, B.I.; Štajn, A.Š. and Saičić, Z.S.: Effect of aspartame on biochemical and oxidative stress parameters in rat blood. Arch. Biol. Sci., 67(2): 535-545 (2015).

- Ross, M.H. and Pawlina, W.: Histology: A Text and Atlas with Correlated Cell and Molecular Biology., 6th Edition, Lippincott Williams and Wilkins, Philadelphia, PA.,USA.(2011).

- Španěl, P.; Dryahina, K.; Vicherková, P. and Smith, D.: Increase of methanol in exhaled breath quantified by SIFT-MS following aspartame ingestion. J. Breath Res., 9(4): 1-7 (2015).

- Stevens, A. and Lowe, J.S.: Human Histology, 3rd Edn., , Elsevier/Mosby, Philadelphia, PA., USA.(2005).

- Sweat, F; Meloan, S. and Putchler, H.: A modified one-step trichrome stain for demonstration of the fine connective tissue fibers. Stain technol., 43: 227-231 (1968).

- Vanni, E.; Bugianesi, E.; Kotronen, A.; De Minicis, S.; Yki-Jarvinen, H. and Svegliati-Baroni, G.: From the metabolic syndrome to NAFLD or vice versa. Dig. Liver Dis., 42: 320-30 (2010).

- Villalobos, G.T.; Pérez, N.H.; Tovar, A.R.; Nava, G.O.; Benítez, B.M.; Villalvazo, I.T.; Ramos, S.M.; Villaseñor, A.D.; Noriega, L.G.; Hiriart, M.; Santillán, R.M.; Hernandez, M.C.C.; Sánchez, N.M.; Uribe, M. and Torres, N.: Combined high-fat 
diet and sustained high sucrose consumption promotes NAFLD in a murine model. Ann. Hepatol., 14(4): 540-546 (2015).

- Wang, M.E.; Chen, Y.C.; Chen, I.S.; Hsieh, S.C.; Chen, S.S. and Chiu, C.H.: Curcumin protects against thioacetamide-induced hepatic fibrosis by attenuating the inflammatory response and inducing apoptosis of damaged hepatocytes. J. Nutr. Biochem., 23(10):1352-1366 (2012).

- White, J.S.: Chapter 2: Sucrose, HFCS, and Fructose: History, Manufacture, Composition, Applications, and Production. Nutrition and Health, p.13-33(2014).

- Yao, Q.Y.; Xu, B.L.; Wang, J.Y.; Liu, H.C.; Zhang, S.C. and Tu, C.T.: Inhibition by curcumin of multiple sites of the transforming growth factor-betal signaling pathway ameliorates the progression of liver fibrosis induced by carbon tetrachloride in rats. BMC Complement Altern. Med., 12: 156 (2012).

- Zhong, L.; Wang, X.; Wang, S.; Yang, L.; Gao, H. and Yang, C.: The anti-fibrotic effect of bone morphogenic protein-7(BMP-7) on liver fibrosis. Int. J. Med. Sci., 10 (4): 441-450 (2013).

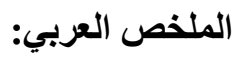

دراسات مقارنه علي تأثير الاسبرتام (محلي صناعي) و الاستيفيا (محلي طبيعي) علي كبد ذكور الجرذان البيضاء. نشوى أحمد فوزى الثناوى ، سميرة أحمد عبد المجيد ، هلير محسن عبد الحميا قسم علم الحيوان ـ كلية البنات للاداب والعلوم والتربيه -جامعة عين شمس

يعد السكروز كواحد من المُحليات مستحضر اً هاماً في أنظمة التخذية الحديثة. إلا أن استخدامه في التحلية يوثر سلباً التهاً

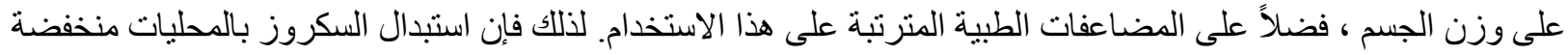

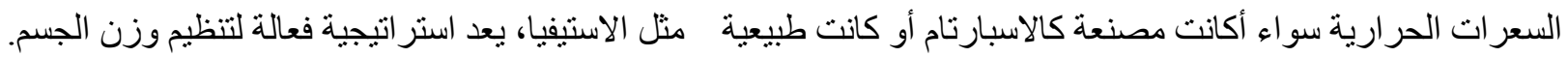

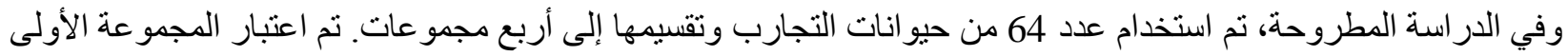

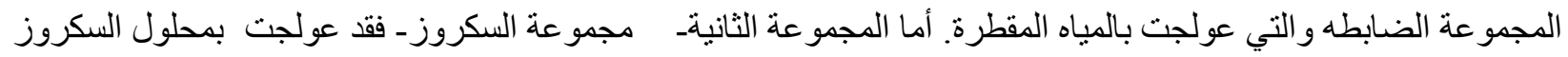

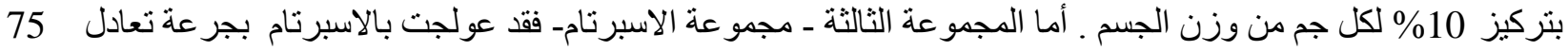

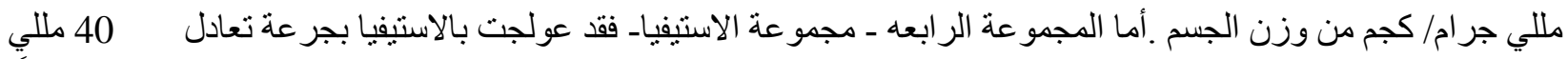
جر ام/ كجم من وزن الجسم. وقد تم تعريض الجرذان لنظامين تجريبيين مقسمين بحسب المدة ، أولهما قصير المدي ( 30 يوماً)

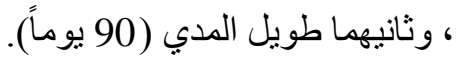

وقد كثفت در اسة لأنسجة الكبد للجرذان لمجموعة الأسبرتام عن ظهور تحلل للاهون، تنخر الخلايا الكبديه، تمدد

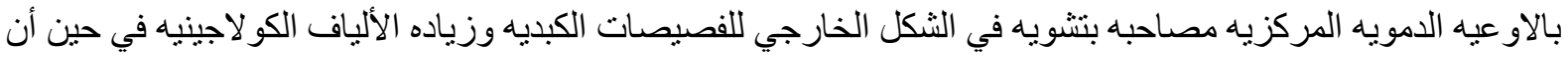

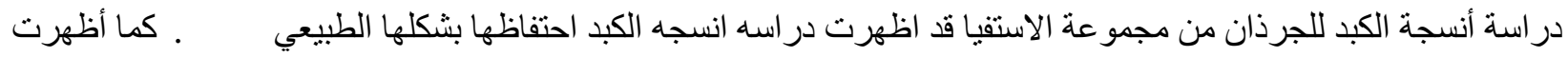

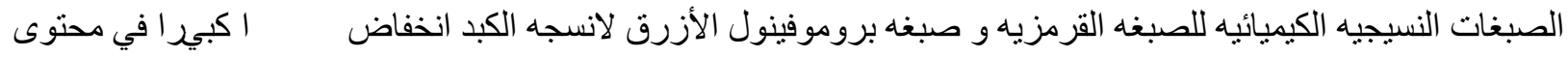

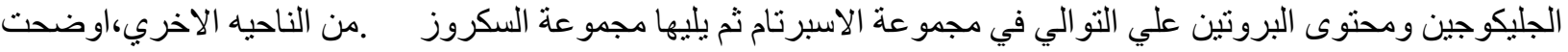

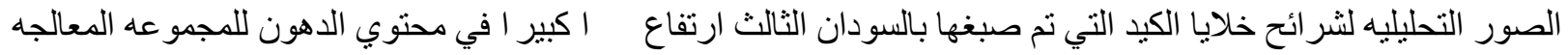

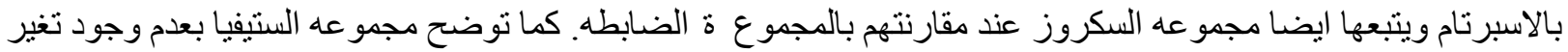

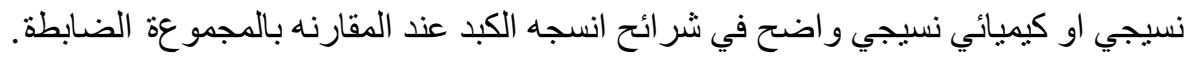

